\title{
Face transplantation: anesthesia and other organizational considerations
}

\section{Transplantation faciale : anesthésie et autres considérations organisationnelles}

\author{
Marie-Eve Bélanger, MD, FRCPC, Pgdip(ed) • Daniel E. Borsuk, MD, MBA, FRCSC • \\ Ariane Clairoux, MD, FRCPC • Louis-Philippe Fortier, MD, FRCPC, MSc $\cdot$ Anh Nguyen, MD, FRCPC • \\ Mihai Georgescu, MD, FRCPC · Philippe Richebé, MD, DESAR, PhD · Issam Tanoubi, MD, DESAR, Ma(ed) • \\ Olivier Verdonck, MD, DESAR, MSc • Quentin Gobert, MD, DESAR
}

Received: 26 July 2020/Revised: 12 November 2020/Accepted: 13 November 2021/Published online: 23 February 2021

(C) Canadian Anesthesiologists' Society 2021

\begin{abstract}
In 2005, the first facial vascularized composite allotransplant was performed in France. In May 2018, our team at Maisonneuve-Rosemont Hospital, Montreal, Quebec, had the privilege to participate in the first facial transplant in Canada. Interdisciplinary collaboration, coordination, and communication formed the cornerstone of this medical undertaking and, ultimately, its success. This report details the anesthetic and organizational considerations of our experience.
\end{abstract}

Résumé En 2005, la première allogreffe de tissu composite vascularisée faciale était réalisée en France. En mai 2018, notre équipe à l'Hôpital MaisonneuveRosemont, à Montréal, au Québec, a eu le privilège de participer à la première greffe faciale au Canada. La collaboration, la coordination et la communication interdisciplinaires ont constitué les pierres angulaires de ce projet médical et, ultimement, de son succès. Ce compte-

M.-E. Bélanger, MD, FRCPC, Pgdip(ed) ( $₫)$.

A. Clairoux, MD, FRCPC - L.-P. Fortier, MD, FRCPC, MSc .

A. Nguyen, MD, FRCPC $\cdot$ M. Georgescu, MD, FRCPC .

P. Richebé, MD, DESAR, PhD .

I. Tanoubi, MD, DESAR, Ma(ed) .

O. Verdonck, MD, DESAR, MSc .

Q. Gobert, MD, DESAR

Department of Anesthesiology and Pain Medicine, Université de Montréal, CIUSSS de l'Est-de-l'Île-de-Montréal, MaisonneuveRosemont Hospital, 5415 Boulevard de l'Assomption, Montréal, QC H1T 2M4, Canada

e-mail: marie_belanger09@hotmail.com

D. E. Borsuk, MD, MBA, FRCSC

Department of Surgery, Université de Montréal, CIUSSS de l'Est-de-l'Île-de-Montréal, Maisonneuve-Rosemont Hospital, Montréal, QC, Canada rendu détaille les considérations anesthésiques et organisationnelles de notre expérience.

Keywords transplantation · multidisciplinarity · craniofacial surgery

In 2005, the first facial vascularized composite allotransplant (VCA) was performed in France. To date, facial VCA remains an exceptional surgical procedure requiring a multidisciplinary team of experts. ${ }^{1-3}$ With advances made on both aesthetic and functional levels, more teams are now pursuing this complex procedure with 44 facial VCAs having been performed worldwide to date. In May 2018, we participated in the first facial transplant in Canada.

The current literature reports many of the essential anesthetic considerations, such as massive blood loss, long procedure duration, and postoperative complications such as acute kidney failure, acute respiratory distress syndrome (ARDS), transplant rejection, thrombosis, and opportunistic infections. ${ }^{4-6}$ Nevertheless, limited data are available relating to the organizational aspects in preparation for this complex surgery., ${ }^{7,8}$ This report details the anesthetic and organizational considerations of our experience, especially the multidisciplinary aspects and other difficulties we faced in carrying out this project.

\section{Early stages}

In 2012, our microsurgery and craniofacial reconstruction program began to recruit a team of surgeons, 
anesthesiologists, intensivists, as well as other physicians and healthcare professionals to build the first Canadian facial VCA team. In 2015, the first prospective VCA candidate was identified. He was a 64 -yr-old male, with no major medical history, who had suffered a gunshot injury in 2011 that avulsed the lower two-thirds of his face (Fig. 1). Despite five conventional reconstructive surgeries, the patient still suffered from major aesthetic and functional limitations, chronic pain, and social isolation, and thus came forth to be considered for a potential facial transplant.

Over the course of the next three years, the multidisciplinary team outlined the medical, surgical, and logistical steps required to ensure success. ${ }^{8}$ The team was able to secure provincial, federal, and institutional support, as well as private funding, for the procedure. The provincial organ procurement organization (Transplant Quebec) worked closely with the transplant team to ensure ethical and transparent handling of potential donor patients and their families. Stringent guidelines for inclusion and exclusion criteria were established for potential donors. Ethics approval for the procedure was granted from Health Canada, Transplant Quebec, as well as our University (University of Montreal) and hospital (Maisonneuve-Rosemont Hospital).

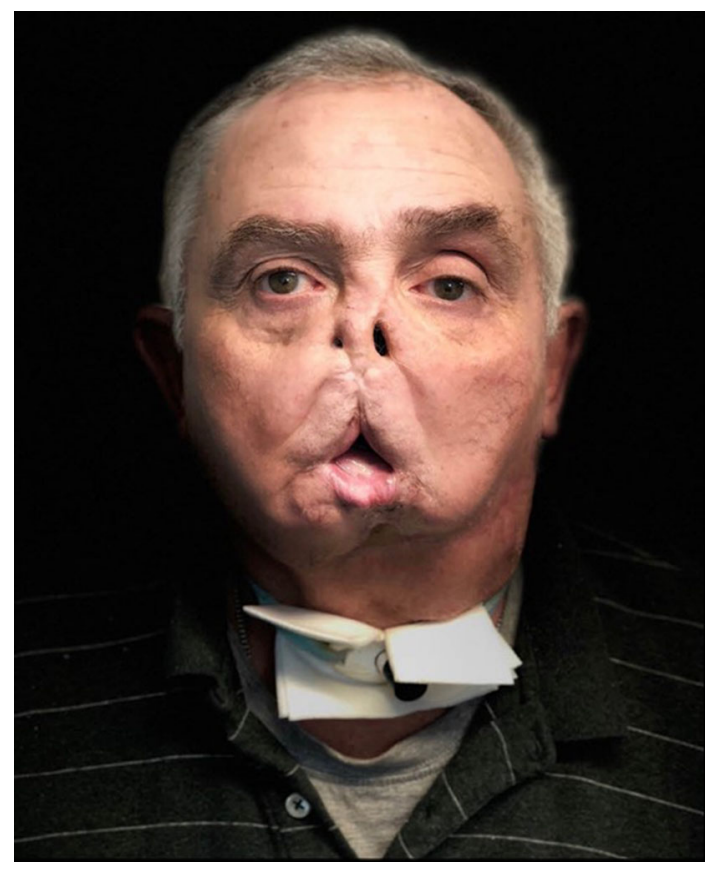

Fig. 1 Recipient prior to face transplant

\section{The multidisciplinary team}

The international experience with facial VCA's has shown the critical importance of selection and preparation of the transplant recipient. ${ }^{9}$ To give full and proper consent for the procedure, the patient must completely understand and accept the delicate balance that exists between the benefits, potential risks, and alternative procedures. The benefits of such procedures include improvements in breathing, mastication, speech, appearance, and consequent social integration. The immediate perioperative risks include rejection, transplant necrosis, and a $15 \%$ mortality rate (six deaths from the 40 facial VCAs have been reported). ${ }^{2,10-12}$ The postoperative risks include the many complications caused by the necessary immunosuppression, including opportunistic infections, rejection, renal impairment, metabolic derangements, and neoplastic disease. ${ }^{6,12}$

Our potential recipient underwent a thorough psychiatric assessment to confirm his ability to deal with the physical and psychological consequences of having to live with a new face. This process also included an assessment of his social support network and his anticipated therapeutic compliance, both of which needed to be highly reliable. ${ }^{12,13}$

The team microbiologist and transplant nephrologist had conducted thorough investigations of the recipient prior to his placement on the waiting list. Along with the pathologist, immunologist, and hematologist, they created a comprehensive immunosuppressant, antibiotic, antiviral, and pathological protocol for the recipient, as cytomegalovirus, herpes simplex virus, candida albicans, pseudomonas, and staphylococcus infections can cause serious complications in $\mathrm{VCA}^{3}$

A specialized surgical team practiced the surgical procedures on cadavers in the three years prior to our patient's operation. This training was critical to minimize surgical risk and optimize the multiple surgical steps that are needed.

From the outset, the head of the anesthesiology department was included in the organization of resources and involved the anesthesia team not only in the perioperative management but also in the management of the recipient's concomitant chronic pain. At the time of transplant, the recipient had been followed in our chronic pain clinic for the three years preceding his transplant. The pain specialist outlined the perioperative pain management protocol for the patient and continues to monitor the patient presently. A group of ten anesthesiologists performed an extensive literature review and had several meetings prior to the surgery. This preparation helped to outline the necessary equipment, operating room (OR) preparation, necessary personnel, and the clinical evaluation needed. The anesthetic protocols for the donor and the recipient 
Table Anesthetic considerations for facial transplant

\begin{tabular}{|c|c|c|}
\hline & Considerations & Solutions \\
\hline 1. & Intraoperative blood loss & $\begin{array}{l}\square \text { Blood bank implication } \\
\bigcirc 10 \text { RBC units reserved for each patient } \\
\text { ODesignated staff available throughout the transplantation } \\
\square \text { Invasive blood pressure monitoring and cardiac output monitoring } \\
\square \text { Perioperative fluid challenges and use of vasoactive drug prn } \\
\square \text { Major venous access } \\
\square \text { Intraoperative intermittent measurement of CBC, coagulation and ABG }\end{array}$ \\
\hline 2. & Long surgical duration & $\begin{array}{l}\square \text { Rigorous positioning and padding } \\
\square \text { Rotation schedule } \\
\square \text { Visual checklists for immunosuppressive and antibiotics agents }\end{array}$ \\
\hline 3. & $\begin{array}{l}\text { Airway and other anesthetic } \\
\text { issues }\end{array}$ & $\begin{array}{l}\text { - Airway management } \\
\text { - Venous and arterial accesses on the lower part of the body } \\
\text { - No neuromuscular blocking drugs } \\
\text { - Free flap surgery considerations } \\
\text { - Awareness of specific complications: air embolism, acute kidney injury, ARDS, TRALI, rejection, infection, } \\
\text { thrombosis, mortality }\end{array}$ \\
\hline 4. & $\begin{array}{l}\text { Concurrent surgical } \\
\text { procedures }\end{array}$ & $\begin{array}{l}\text { - Donor and recipient team coordination } \\
\text { - Specific schedule for each patient } \\
\text { - Visual aids for the surgical phases } \\
\text { - Solid organs procurement priority }\end{array}$ \\
\hline 5. & Multidisciplinary & $\begin{array}{l}\text { - Immunosuppressive and antibiotic protocols to be managed with anesthesiologists with the help of the } \\
\text { - Donor preparation by the ICU } \\
\text { - Silicon mask for donor's dignity }\end{array}$ \\
\hline
\end{tabular}

$\mathrm{ABG}=$ arterial blood gas; $\mathrm{ARDS}=$ acute respiratory distress syndrome; $\mathrm{CBC}=$ complete blood count; $\mathrm{ICU}=$ intensive care unit; $\mathrm{RBC}=$ red blood cell; TRALI $=$ transfusion related lung injury

were established by the assigned anesthesia team and intensive care specialists, who were responsible for preand postoperative care of both the donor and recipient.

The nurses and respiratory therapists (RT) on the team also had access to the cadaver training sessions to become more familiar with the procedure.

\section{Preparation and organization}

\section{Anesthetic considerations}

The literature review helped identify some possible difficulties to be encountered during a VCA procedure, including the following:

\section{Intraoperative blood loss}

During the dissection of the recipient's face, the osteotomies and the graft reperfusion are two highly hemorrhagic phases that can require a massive transfusion. Several studies have reported significant transfusion requirements with a median of 20 units of packed red blood cells (RBCs), 13 units of fresh frozen plasma, and 13 units of platelets. ${ }^{4-6}$ This massive blood loss can lead to hemodynamic instability that needs to be closely monitored with invasive arterial (and/or cardiac output monitoring) and treated with appropriate administration of fluid and vasopressors. $^{4-6}$ The use of vasopressors in free flap surgery is still controversial, despite animal and observational studies showing no deleterious effect. ${ }^{14}$ To date, there are no studies assessing the effects of vasopressors on free flap outcomes, or favouring one from another, thus we chose norepinephrine as it is commonly used in the OR and intensive care unit (ICU), and has been reported in previous facial VCAs., ${ }^{4,6,15}$

Lengthy surgical time

Previously published studies have reported a mean surgical duration of $20 \mathrm{hr}$ for the recipient, and $12-15 \mathrm{hr}$ for the donor. ${ }^{4-6}$ Because of this long duration, we planned to have several anesthesiologists involved on a rotating schedule to cover both procedures. This required careful 
communication and thorough documentation during the transfers to maintain all the intraoperative protocols. ${ }^{16}$

Airway and other anesthetic issues

Upper airway management can be difficult on a recipient who has had prior complex facial trauma and surgical management. A preoperative assessment of the airway is critical to plan its subsequent safe management. ${ }^{5,16}$ As central venous access is required for the administration of vasopressors, the femoral vein was preferred to avoid the surgical teams that would be working in the neck area as well as to avoid trauma (and possible associated thrombosis) of the jugular or subclavian veins that could then jeopardize the surgical procedure. ${ }^{4-6,16}$ Even though no specific anesthetic agent has been shown to be superior for a face transplant, sevoflurane has frequently been used for this specific surgery, in part because of theoretical beneficial effects on the microcirculation during ischemia and reperfusion. ${ }^{5,6,17}$

Neuromuscular blocking agents are contraindicated during the dissection and nerve coaptation phases of the surgery. A remifentanil infusion can help prevent intraoperative movements. ${ }^{4,16}$ Hypothermia should be avoided with the use of warming blankets and intravenous fluid warmers. Regular respiratory recruitment maneuvers should be used to help reduce atelectasis. Pulmonary function should be closely monitored by intermittent arterial gas measurements as hypoxia and hypocapnia can impair the oxygenation and blood flow to the graft. $^{6}$ Reverse Trendelenburg positioning $\left(15^{\circ}\right)$ is used to facilitate venous drainage of the upper body and to limit blood loss. Nevertheless, it can increase the risk for air embolism. ${ }^{4,6}$ As stated previously, over 40 facial transplantations has been realized worldwide, with six deaths reported in the literature (overall mortality rate, 15\%) as a result of infections, organ rejection, multiorgan failure, malignancy, or suicide. ${ }^{2,10-12}$ Major postoperative complications, such as renal failure, transfusion related lung injury, ARDS, opportunist infections, and vascular thrombosis, have been reported, but their occurrences are unpredictable because limited data are available. ${ }^{3,6,11,12}$ Nevertheless, it has been reported that $100 \%$ of recipients experienced one or more episodes of rejection, acute or chronic, managed with modification of the immunosuppressive therapy. ${ }^{11}$

Concurrent surgical procedures (donor and recipient)

The planning of any needed concurrent surgical procedures on either the donor and recipient prior to the VCA was also considered. Effectively coordinating the face procurement and the recipient preparation is crucial to minimize the graft ischemic time, which should be less than four hours. $^{3,7}$ To reduce graft ischemia, the donor facial procurement occurs prior to the start of any other concomitant solid organ procurement. $^{3,7}$ The anesthesiologist in charge of the donor must maintain constant hemodynamic stability during the facial dissection, which can be challenging given the potential blood loss added to the physiologic changes observed on brain-dead donors. ${ }^{7,16}$ As life-saving organs remain the priority through the entire donor harvesting procedure, the thorax and abdomen must be accessible at all times to allow quick procurement of solid organs in case of major hemodynamic instability that cannot be reversed. Such an event could also lead to a premature interruption of the face procurement. ${ }^{7}$ Constant communication between the donor and the recipient teams is crucial to ensure that nerve sectioning and immunosuppressive induction in the recipient only begins when the donor team is confident it can successfully complete the entire facial procurement.

\section{Multidisciplinary considerations}

The prospect of a long operation and the rotating of a succession of different anesthesiologists led us to develop a specific strategy for the administration of antibiotics and immunosuppressive therapies. Several meetings with the microbiology, immunology, and pharmacy teams helped to incorporate specific drug administration protocols by the anesthesia team. When possible, it was decided to administer antibiotics and immunosuppressants as continuous infusions. Different checklists were displayed on the walls of the OR providing optimal clarity regarding the drug administration procedures. The donor's preoperative care in the ICU was also discussed, as some aspects were patient specific and differed from those of standard solid organ donors. For example, the placement of the arterial and venous access on the femoral vessels and a preoperative surgical tracheostomy are essential. ${ }^{4,7}$ There are also compassionate considerations for the family and the donor patient. Thus, an artist is part of the multidisciplinary team to create a high-fidelity silicon mask once the family consents to face procurement. This mask would be placed on the donor's explanted face prior to leaving the OR to respect the donor patient and their family. ${ }^{7}$

\section{Organizational and other logistical considerations}

It was crucial for the head of the anesthesiology department and team leader to observe one of the cadaver training sessions to identify the critical surgical phases, understand 
the optimal placement/location of each team member in the OR (Fig. 2), and determine the resources needed for a simultaneous harvest and transplant in the same/adjacent OR complex. As VCA transplantation is a time-consuming operation, at least two different ORs need to be dedicated to the procedure, ideally without affecting other elective or urgent surgical activities. A special team of nurses, RTs (always assigned to our OR to work alongside the anesthesiologist), OR support staff, and pharmacists would be working continuously, in addition to the regular teams. At least four anesthesiologists were required to ensure a proper continuous care of the two patients. Although we had initially planned to do the procedure on a weekend, the team realized that there would not be enough OR support staff available so a weekday was thought to be more suitable for such a major undertaking.

\section{One day before the transplant}

When we confirmed that a potential donor had been identified, we began working on the anesthesiologist rotation schedule, including the nurses and RTs (Fig 3). We took advantage of a mandatory 48 -hr delay required for all the immunology tests before the procedure can be performed. The scheduled elective patients undergoing

Fig. 2 Operating room organization *Organ donor

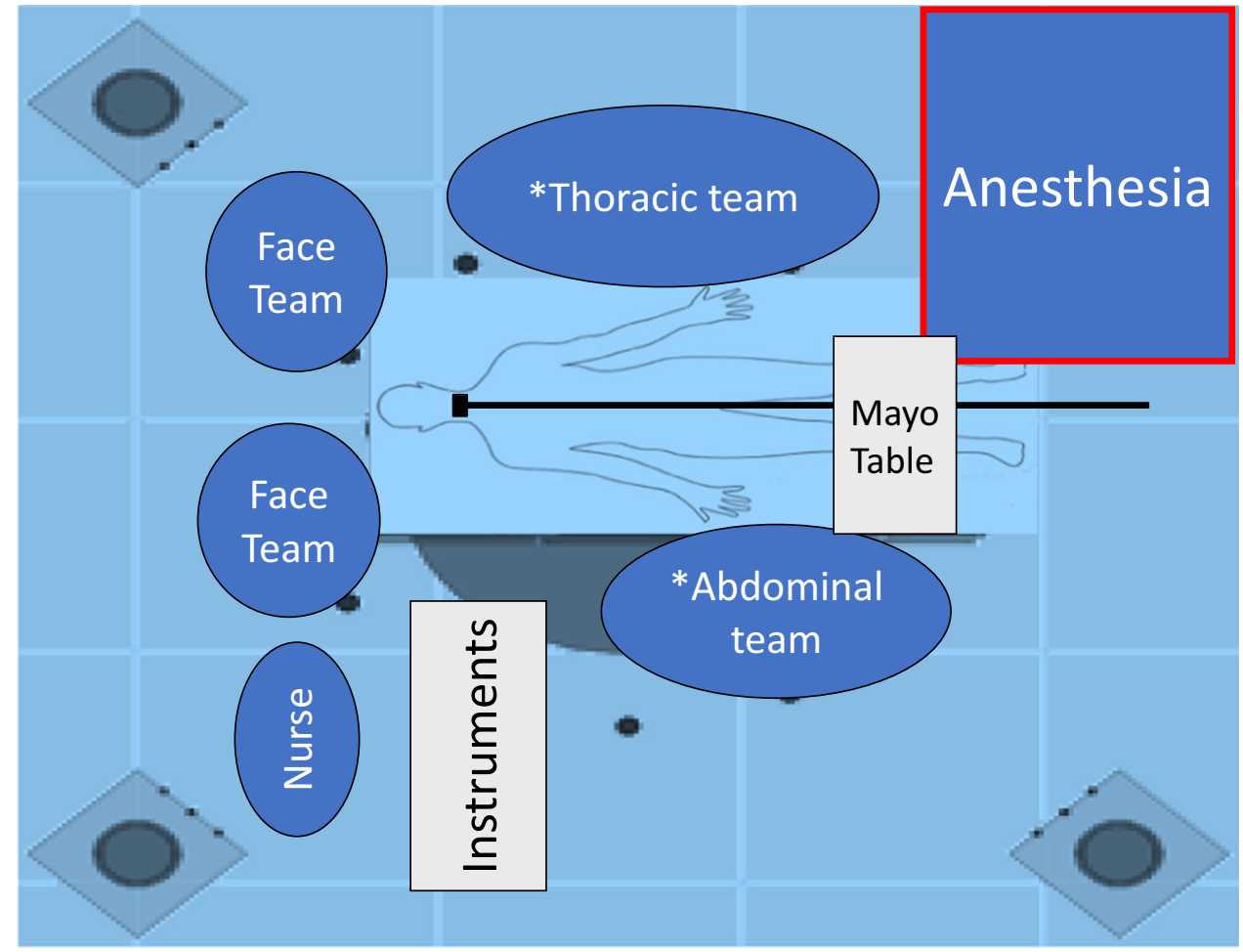

\begin{tabular}{|c|c|c|c|c|c|c|c|c|c|}
\hline \multirow[b]{3}{*}{ Donor } & $6 \mathrm{~h}$ & $10 \mathrm{~h}$ & $14 \mathrm{~h}$ & $18 \mathrm{~h}$ & $22 \mathrm{~h}$ & $2 \mathrm{~h}$ & $6 h$ & $10 \mathrm{~h}$ & $14 \mathrm{~h}$ \\
\hline & & A2 & & & & \multicolumn{2}{|c|}{ ON-call team } & & \\
\hline & & A4 & A4 PRN & & & & & & \\
\hline \multirow[b]{2}{*}{ Recipient } & \multicolumn{3}{|l|}{ A1 } & \multicolumn{3}{|l|}{ A3 } & A1 & & \\
\hline & A5 & A5 PRN & & A1 PRN & A5 PRN & & & & \\
\hline
\end{tabular}

\begin{tabular}{|l|l|}
\hline A1 & Recipient; available to help A3 until 22h \\
A2 & Donor (face procurement) \\
A3 & Relay A1 for night shift \\
A4 & Assist A2 for induction; available to help during face procurement if needed \\
A5 & Assist A1 for induction; available to help during face transplantation if needed \\
\hline
\end{tabular}

Fig. 3 Anesthesiologists' rotation schedule 
either plastic or other head and neck procedures were cancelled as the surgeons were anticipated to be occupied with the transplant. The support staff initially scheduled to work within these specialty areas were automatically assigned to work on the face transplant.

The donor was a middle-aged Caucasian male whose neurologic death had been confirmed a few hours after he was admitted to an outside hospital. After the family gave consent for the organ and face donation, the patient was transferred to our institution. In addition to his face, other solid organ (heart, liver, and kidneys) donations were also planned. He developed central diabetes insipidus that was quickly treated with desmopressin. Thrombocytopenia and anemia were also corrected preoperatively. As planned, the ICU team acquired the anticipated femoral vascular access. A surgical tracheostomy and a jaw fixation were performed the day before the transplant to facilitate the facial mask production.

Once the cross-match confirmed donor compatibility, the anesthesia team completed the pre-anesthetic evaluation of the recipient and answered all remaining questions. A peripherally inserted central catheter (PICC line) was placed to start the preoperative immunosuppressive therapy. The blood bank was alerted to the potential high blood demand, and 10 units of RBCs were prepared for both donor and recipient.

\section{Day of surgery}

The recipient's surgical procedure began four hours before the donor's because of the anticipated difficulties in dealing with the scar tissue caused by the initial injury and subsequent reconstructive surgeries.

\section{The recipient}

Standard patient monitoring was applied ${ }^{18}$ in addition to a thoracic bioreactance cardiac output monitor (Non Invasive Cardiac Output Monitor [NICOM], Cheetah medical Inc, Newton, MA, USA) and an analgesia monitor (Nociception level index (NOL), PMD100 Medasense Biometrics Ltd., Ramat Yishai, Israel). Anesthesia was induced with propofol and remifentanil. An 8.0-armoured endotracheal tube was inserted into the tracheostomy site and sutured to the thorax. Venous access consisted of a PICC line inserted in the left arm, an 18G intravenous catheter on the right arm, and a right femoral triple-lumen central venous catheter. A right femoral and a right radial arterial catheter were inserted for invasive blood pressure monitoring and blood sampling. Hypothermia was prevented with the use of a fluid warmer (Ranger3M, 3M Company, St-Paul, MN, USA) and two forced air warming system with lower and under body blankets (Bear Hugger 3M, 3M Company, StPaul, MN, USA).

Anesthesia was maintained with sevoflurane and a remifentanil infusion. Remifentanil was chosen for its very low context sensitive half-life allowing for optimal hemodynamic stability, especially during the low stimulation surgical phases where the remifentanil infusion could be rapidly adjusted according to the NOL index. A ketamine infusion $\left(0.25 \mathrm{mg} \cdot \mathrm{kg}^{-1} \cdot \mathrm{hr}^{-1}\right)$ was maintained throughout the surgery to minimize postoperative pain.

Cardiac output of the patient was maintained at baseline levels using fluid response challenge-based optimization; pulse pressure variation was also used to direct fluid optimization. The mean arterial pressure (MAP) was maintained $>65 \mathrm{mmHg}$ with the use of norepinephrine after the $\mathrm{CO}$ had been optimized. The maximal rate of norepinephrine used was $0.08 \mu \mathrm{g} \cdot \mathrm{kg}^{-1} \cdot \mathrm{min}^{-1}$ during a higher blood loss phase. After $30 \mathrm{hr}$ of surgery, the estimated blood loss was $2,000 \mathrm{~mL}$. The patient received $10.1 \mathrm{~L}$ of crystalloid, $500 \mathrm{~mL}$ of $5 \%$ albumin, and 2 units RBCs. Hemoglobin was maintained $>90 \mathrm{~g} \cdot \mathrm{L}^{-1}$.

There was no occurrence of hypoxia during the procedure and the fraction of inspired oxygen $\left(\mathrm{F}_{1} \mathrm{O}_{2}\right)$ was maintained between 60 and $65 \%$ throughout. Arterial gas analysis showed a gradual increase in the gap between the end-tidal $\mathrm{CO}_{2}$ and the arterial pressure of carbon dioxide, partly due to the increased shunt from the posterior atelectasis that occurred despite regular recruitment maneuvers. The positive end-expiratory pressure was set at $6 \mathrm{cmH}_{2} \mathrm{O}$ at the start of the surgery and gradually increased to $10 \mathrm{cmH}_{2} \mathrm{O}^{6}$ These maneuvers helped stabilize $\mathrm{PaCO}_{2}$, but were limited to avoid increasing venous congestion in the graft. Optimal coordination between the donor and recipient teams resulted in a graft ischemic time of only $110 \mathrm{~min}$.

\section{The donor}

Standard patient monitoring was used, as well as continuous $\mathrm{CO}$ and stroke volume variation (SVV) monitoring (FloTrac, Edwards Lifesciences Corp, Irvine, CA, USA) using a femoral arterial catheter. The previously placed tracheostomy canula was replaced by an armed 8.0 ET tube that was sutured to the skin just distal to the clavicle to allow access to perform a sternotomy for the solid organ procurement. Remifentanil and sevoflurane were administered to prevent spinal reflexes as muscle relaxant were not permitted during the nerve dissection of the face.

Urine output was maintained between 1 and 1.4 $\mathrm{mL} \cdot \mathrm{kg}^{-1} \cdot \mathrm{hr}^{-1}$. A vasopressin infusion was started at 0.5 $\mathrm{U} \cdot \mathrm{hr}^{-1}$ to treat an increased diuresis related to the 
development of diabetes insipidus. The MAP was maintained at $70 \mathrm{mmHg}$ with normal values of $\mathrm{CO}$ and SVV during the entire procedure. No other vasopressors were required during the face procurement.

The allograft was a partial osteomyocutaneous graft, including the upper and lower jaws, inferior orbits, nose, lower eyelids, lips, muscles, nerves, and face skin. Considering the extensive graft and the numerous osteotomies, a lengthy procedure and major blood loss were anticipated. The facial dissection time was $14 \mathrm{hr}$. Regular testing for hemoglobin, platelet count, electrolytes and blood gases occurred during that phase. The donor patient was given $6 \mathrm{~L}$ of crystalloids as well as 4 units of RBCs and 10 units of platelets. The total blood loss during the facial procurement was $1,100 \mathrm{~mL}$ and mainly occurred during the facial osteotomies. The hemoglobin was maintained $>80 \mathrm{~g} \cdot \mathrm{L}^{-1}$ in anticipation of potential major blood loss during the facial osteotomies and during the procurement of other solid organs. The $\mathrm{F}_{1} \mathrm{O}_{2}$ was kept between 60 and $70 \%$ and no respiratory events were reported. The procurement of the other organs lasted four more hours for a total surgical time of $18 \mathrm{hr}$. The total estimated blood loss was $1,400 \mathrm{~mL}$. The silicon mask was sutured onto the patient after the surgery was completed and before the donor was removed from the OR.

\section{Postoperative course}

After $30 \mathrm{hr}$ of surgery, the facial transplantation was completed, and the recipient was transferred to the ICU while sedated with fentanyl, ketamine, and midazolam infusions (Fig. 4). The patient was then treated by the chronic pain specialists, as most of his usual medication (pregabalin, nabilone, and quetiapine) had to be discontinued intraoperatively for lack of intravenous formulation. The patient had drug withdrawal syndrome for three days and had to be treated for recalcitrant neuropathic pain by the collaborative work of intensivists, surgeons, and chronic pain specialists. He remained in the ICU for seven days because of postoperative delirium, intense pain, and pneumonia. The tracheostomy was removed on postoperative day 12 . The patient left the hospital for a rehabilitation centre 60 days after surgery.

\section{Conclusions}

More than 100 healthcare professionals participated in completing this first facial transplant in Canada (Fig 5). The excellent interdisciplinary collaboration, coordination, and communication was the cornerstone of this medical undertaking and its ultimate success. Rigorous anesthesia

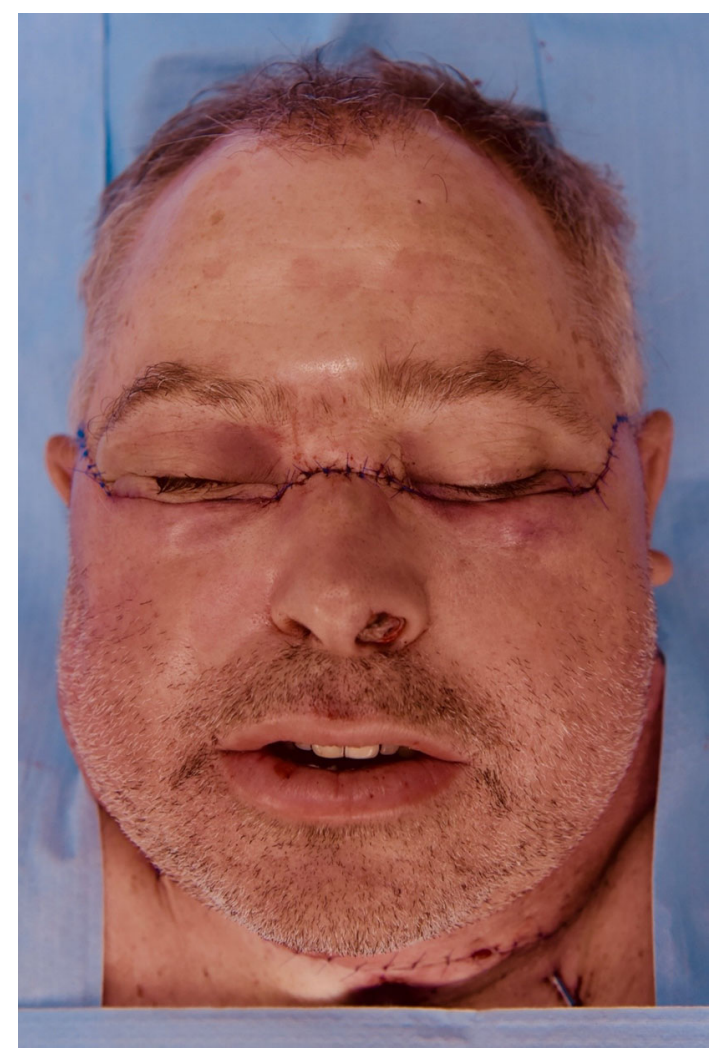

Fig. 4 Recipient immediately after facial transplantation

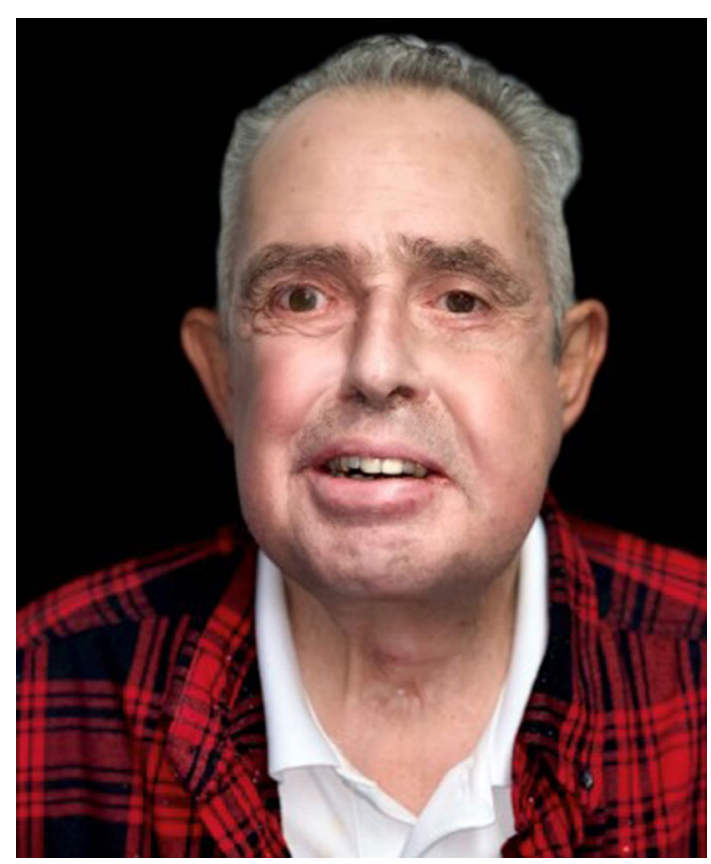

Fig. 5 Recipient after facial transplantation

protocols were essential in both limiting the hemorrhagic, infectious, and immunologic risks, as well as optimizing the graft condition and maintaining ideal conditions for the 
solid organs to be procured. The checklists proved crucial in mitigating mistakes in the administration of antibiotic and immunosuppressive therapies. The optimization of drug administration through continuous infusions avoided any dosing errors and maintained an optimal bioavailability regardless of blood loss.

Despite a thorough preoperative review of literature and discussion with other VCA teams, we were not adequately prepared for the intense pain and consequent postoperative delirium that impacted and delayed the patient's early recovery. The ketamine infusion did not seem to reduce any postoperative hyperalgesia. Other co-analgesic drugs, such as IV lidocaine, could have been considered to limit this phenomenon after a face transplant. The NOL monitoring allowed us to titrate the amount of opioid that we used during the non-stimulating phases of the surgery. ${ }^{19}$

Finally, the synchronization of the two different surgeries was very important to reduce the ischemic time of the graft to a minimum and to allow the other organs of the donor to be procured in an optimal time. ${ }^{20}$

Author contributions Marie Eve Bélanger, Ariane Clairoux, Olivier Verdonck, and Quentin Gobert contributed to study execution and manuscript writing and revision, and agree with the content of the article. Daniel Borsuk, Louis-Philippe Fortier, Anh Nguyen, and Mihai Georgescu contributed to all aspects of study execution and manuscript revision and agree with the content of the article. Philippe Richebé contributed to manuscript writing and revision and agrees with the content of the article. Issam Tanoubi contributed to study execution and manuscript revision and agrees with the content of the article.

Disclosures None.

\section{Funding statement None.}

Editorial responsibility This submission was handled by Dr. Hilary P. Grocott, former Editor-in-Chief, Canadian Journal of Anesthesia.

\section{References}

1. Devauchelle B, Badet L, Lengele B, et al. First human face allograft: early report. Lancet 2006; 368: 203-9.

2. Farber SJ, Kantar RS, Diaz-Siso JR, Rodriguez ED. Face transplantation: an update for the United States trauma system. J Craniofac Surg 2018; 29: 832-8.

3. Smeets $R$, Rendenbach $C$, Birkelbach $M$, et al. Face transplantation: on the verge of becoming clinical routine? Biomed Res Int 2014; DOI: https://doi.org/10.1155/2014/907272.
4. Dalal A. Face transplantation: anesthetic challenges. World J Transplant 2016; 6: 646-9.

5. Edrich T, Cywinski JB, Colomina MJ, et al. Perioperative management of face transplantation: a survey. Anesth Analg 2012; 115: 668-70.

6. Sedaghati-nia A, Gilton A, Liger $C$, et al. Anaesthesia and intensive care management of face transplantation. $\mathrm{Br} \mathrm{J}$ Anaesth 2013; 111: 600-6.

7. Brazio PS, Barth RN, Bojovic B, et al. Algorithm for total face and multiorgan procurement from a brain-dead donor. Am J Transplant 2013; 13: 2743-9.

8. Siemionow $M$, Gordon CR. Overview of guidelines for establishing a face transplant program: a work in progress. Am J Transplant 2010; 10: 1290-6.

9. Tasigiorgos $S$, Kollar B, Krezdorn N, Bueno EM, Tullius SG, Pomahac B. Face transplantation-current status and future developments. Transpl Int 2018; 31: 677-88.

10. Lubek JE. Facial transplantation: what does the future hold? Oral Surg Oral Med Oral Pathol Oral Radiol 2019; 128: 345-6.

11. Siemionow $M$. The decade of face transplant outcomes. J Mater Sci Mater Med 2017; DOI: https://doi.org/10.1007/s10856-0175873-z.

12. Theodorakopoulou E, Meghji S, Pafitanis G, Mason KA. A review of the world's published face transplant cases: ethical perspectives. Scars Burn Heal 2017; DOI: https://doi.org/10. $1177 / 2059513117694402$.

13. Lantieri L, Grimbert P, Ortonne N, et al. Face transplant: longterm follow-up and results of a prospective open study. Lancet 2016; 388: 1398-407.

14. Wax $M K$, Azzi J. Perioperative considerations in free flap surgery: a review of pressors and anticoagulation. Oral Oncol 2018; 83: 154-7.

15. Ibrahim AM, Kim PS, Rabie AN, Lee BT, Lin SJ. Vasopressors and reconstructive flap perfusion: a review of the literature comparing the effects of various pharmacologic agents. Ann Plast Surg 2014; 73: 245-8.

16. Cywinski JB, Doyle DJ, Kusza K. Anesthetic care for face transplantation. In: Siemionow M (Ed.). The Know-How of Face Transplantation. NY: Springer-Verlag London; 2011: 95-102.

17. Lucchinetti E, Ambrosio S, Aguirre $J$, et al. Sevoflurane inhalation at sedative concentrations provides endothelial protection against ischemia-reperfusion injury in humans. Anesthesiology 2007; 106: 262-8.

18. Dobson $G$, Chow L, Filteau L, et al. Guidelines to the practice of anesthesia - revised edition 2020. Can J Anesth 2020; 67: 64-9.

19. Renaud-Roy E, Stockle PA, Maximos S, et al. Correlation between incremental remifentanil doses and the Nociception Level (NOL) index response after intraoperative noxious stimuli. Can J Anesth 2019; 66: 1049-61.

20. Tullius $S G, R a b b H$. Improving the supply and quality of deceased-donor organs for transplantation. N Engl J Med 2018; 379: 693-4.

Publisher's Note Springer Nature remains neutral with regard to jurisdictional claims in published maps and institutional affiliations. 